Jurnal Informatika dan Rekayasa Perangkat Lunak (JATIKA)
Vol. 1, No. 2, December 2020, 264-273
ISSN 2723-3367
available online at:http:///im.teknokrat.ac.id/index.php/informatika

\title{
SISTEM INFORMASI MONITORING KINERJA SDM (STUDI KASUS: PT PLN UNIT PELAKSANA PEMBANGKITAN TARAHAN)
}

\author{
M. Diego Bryllian ${ }^{1}$, Kisworo ${ }^{2}$ \\ Universitas Teknokrat Indonesia ${ }^{1,2}$ \\ mdiegobryllian@gmail.com
}

Received: (30 Desember 2020)Accepted: (31 Desember 2020) Published: (31 Desember 2020)

\begin{abstract}
PT PLN (Persero) Tarahan Generation Implementing Unit is one of the electricity provider services which has the main objective of striving for generation in sufficient quantity and quality as well as doing business with sound economic principles, paying attention to the interests of stakeholders and increasing the interests of customer satisfaction. In one of the main activities of PT PLN (Persero), the Tarahan Generation Implementing Unit has ways of managing Human Resources (HR), namely Human Capital Readiness (HCR) and Organization Capital Readiness (OCR). HCR is the readiness of human resources capacity and capability in supporting the implementation of the Company's strategy, while OCR is the readiness of the organization in integrating and aligning factors that encourage continuous improvement and learning to support the organizational change agenda through the implementation of the Company's strategy. HCR and OCR itself are carried out by the HR department and are the most important factors in assessing the Organizational Performance Value, especially in performance appraisals. Some small mistakes will have a big impact if the performance value of the HR department is not achieved. The HR Performance Monitoring Information System aims to monitor the achievements every month so that the HR department can achieve the performance targets. The system development method uses a prototype, the design tool uses UML modeling which consists of use cases, activity diagrams and class diagrams. Making the system usingapplications Adobe Dreamweaver and MySQL. Based on the calculation of the questionnaire data, it can be concluded that the level of service provided is good with numbers valued at $89.09 \%$ and $91.55 \%$. So, with the monitoring information system that has been implemented at PT PLN (Persero), the Tarahan Generation Implementing Unit is realized well.
\end{abstract}

Keywords: Information Systems, Performance Monitoring, Key Performance Indicator (KPI), UML

\begin{abstract}
Abstrak
PT PLN (Persero) Unit Pelaksana Pembangkitan Tarahan merupakan salah satu jasa penyedia listrik yang memiliki tujuan pokok yaitu mengusahakan pembangkitan dalam jumlah dan mutu yang memadai serta melakukan usaha dengan kaidah ekonomi yang sehat, memperhatikan kepentingan stakeholder serta meningkatkan kepentingan kepuasan pelanggan. Di dalam salah satu kegiatan pokok PT PLN (Persero) Unit Pelaksana Pembangkitan Tarahan memilki cara pengelolaan Sumber Daya Manusia (SDM), yaitu Human Capital Readiness (HCR) dan Organization Capital Readiness (OCR). HCR adalah kesiapan kapasitas dan kapabilitas SDM dalam mendukung implementasi strategi Perusahaan, sedangkan OCR adalah kesiapan organisasi dalam mengintegrasikan dan menyelaraskan faktor yang mendorong perbaikan dan pembelajaran berkelanjutan untuk
\end{abstract}


mendukung agenda perubahan organisasi melalui implementasi strategi Perusahaan. HCR dan OCR sendiri dilaksanakan oleh bagian SDM dan merupakan factor paling penting dalam penilaian Nilai Kinerja Organisasi terutama dalam penilaian kinerja. Beberapa kesalahan kecil akan berdampak besar apabila nilai kinerja bagian SDM tidak tercapai. Sistem Informasi Monitoring Kinerja SDM bertujuan untuk memantau pencapaian setiap bulannya agar bagian SDM dalam mencapai target kinerja. Metode pengembangan sistem menggunakan prototype, alat perancangan menggunakan pemodelan UML yang terdiri dari use case, activity diagram dan class diagram. Pembuatan sistem menggunakan aplikasi Adobe Dreamweaver dan MySQL. Berdasarkan perhitungan data kuesioner dapat disimpulkan bahwa tingkat pelayanan yang diberikan yaitu baik dengan angka senilai $89.09 \%$ dan $91.55 \%$. Sehingga, dengan adanya sistem informasi monitoring yang telah diterapkan di PT PLN (Persero) Unit Pelaksana Pembangkitan Tarahan terwujud dengan baik.

Kata Kunci: Sistem Informasi, Monitoring Kinerja, Key Performance Indicator (KPI), UML

\section{To cite this article:}

M. Diego Bryllian, Kisworo. (2020). SISTEM INFORMASI MONITORING KINERJA SDM (STUDI KASUS: PT PLN UNIT PELAKSANA PEMBANGKITAN TARAHAN). Jurnal Informatika dan Rekayasa Perangkat Lunak, Vol(1) No(2), 264-273.

\section{PENDAHULUAN}

Dalam era globalisasi, masalah sumber daya manusia menjadi sorotan maupun tumpuan bagi perusahaan untuk tetap dapat bertahan. Dengan banyaknya sarana dan prasarana tanpa dukungan sumber daya manusia yang baik maka kegiatan perusahaan tidak akan berjalan dengan baik dan dengan demikian sumber daya manusia merupakan kunci pokok yang harus diperhatikan sehingga sumber daya manusia akan menentukan keberhasilan pelaksanaan kegiatan perusahaan (Megawaty et al., 2020). Unsur sumber daya manusia di dalam perusahaan salah satunya adalah karyawan. PT PLN (Persero) Unit Pelaksana Pembangkitan Tarahan berlokasi di Desa Rangai Tri Tunggal (DesaTarahan), Kecamatan Ketibung, Kabupaten Lampung Selatan, memiliki tujuan pokok yaitu mengusahakan pembangkitan dan penyediaan listrik dalam jumlah dan mutu yang memadai serta melakukan usaha sesuai dengan kaidah ekonomi yang sehat, memperhatikan kepentingan stakeholder serta meningkatkan kepuasan pelanggan. Dalam upaya menjaga kinerja karyawan maka harus di jaga pula kepuasan karyawan, dalam hal ini PT PLN (Persero) Unit Pelaksana Pembangkitan Tarahan memberikan fasilitas Pengembangan Kinerja Pegawai melalui Program Pengukuran Human Capital Readiness (HCR) dan Organization Capital Readiness (OCR) yang tertuang dari surat PT PLN (Persero) Kantor Pusat nomor 0461/SDM.05.01/DIVHCMS/2016 tanggal 15 Maret 2016 Perihal Pedoman Pengukuran Kinerja SDM tahun 2016. HCR adalah kesiapan kapasitas dan kapabilitas SDM dalam mendukung implementasi strategi Perusahaan, sedangkan OCR adalah kesiapan organisasi dalam mengintegrasikan dan menyelaraskan faktor yang mendorong perbaikan dan pembelajaran berkelanjutan untuk mendukung agenda perubahan organisasi melalui implementasi strategi Perusahaan (Setiawansyah, Sulistiani and Darwis, 2020).

Dalam pelaksanaan HCR dan OCR, karyawan dibantu oleh bagian SDM \& Umum khususnya dalam proses administrasi agar dapat berjalan sesuai dengan ketentuan yang berlaku, seperti program sertifikasi, penugasan pegawai, pendidikan, pelatihan, knowledge management, tandem, dan lain sebagainya. Kinerja HCR dan OCR dapat dicapai dengan beberapa kriteria yang harus dipenuhi oleh bagian SDM \& Umum, namun kesalahan yang dilakukan oleh Bagian SDM dalam proses pemenuhan target kinerja HCR dan OCR dapat mengakibatkan terjadi resiko penurunan Nilai Kinerja Organisasi (NKO). Masalah tersebut hendak diselesaikan dengan Metode KPI (Key Perfomance Indicator). Metode ini bertujuan untuk mengukur kinerja Perusahaan dengan menggunakan indicator. Kelebihannya adalah pegawai dapat melihat indicator apa saja yang dapat mencapai kinerja perusahaan. Adapun kekurangannya yaitu banyak pegawai yang secara sengaja menghindari pemeilihan KPI yang relatif sulit dicapai. Penulis mengambil metode ini dikarenakan memudahkan perusahaan dalam memonitoring target - target kinerja. 
Adanya sistem ini diharapkan dapat memberikan solusi dalam mengatasi masalah yang terjadi dalam perusahaan yang serta menurunkan resiko dari beberapa faktor tidak tercapainya kinerja bagian SDM PT PLN (Persero) Unit Pelaksana Pembangkitan Tarahan dengan menggunakan metode Key Performance Indicator (KPI) dan analisis PIECES (Performance, Information, Economy, Control, Eficiency and Service).

\section{TELAAH PUSTAKA \\ Monitoring Kinerja}

Menurut Mangkunegara "hasil kerja secara kualitas dan kuantitas yang dicapai oleh seorang pegawai dalam melaksanakan tugasnya sesuai dengan tanggung jawab yanng diberikan kepadanya". Kualitas yang dimaksud disini adalah dilihat dari kehalusan, kebersihan dan ketelitian dalam pekerjaan sedangkan kuantitas dilihat dari jumlah atau banyaknya pekerjaan yang harus diselesaikan karyawan (Mangkunegara, 2005).

\section{Key Performance Indicator}

Key Performance Indicator (KPI) atau disebut juga sebagai Key Success Indicator (KSI) adalah satu set ukuran kuantitatif yang digunakan perusahaan atau industri untuk mengukur atau membandingkan kinerja dalam hal memenuhi tujuan strategis dan operasional mereka. KPI bervariasi antar perusahaan atau industri, tergantung pada prioritas atau kriteria kinerja. KPI dibuat setelah sebuah organisasi memiliki strategi dan tujuannya, KPI membantu organisasi memastikan seberapa jauh kemajuan tujuan yang telah dan akan dicapainya (Parmenter, 2015)

\section{METODE PENELITIAN}

\section{Kerangka Penelitian}

Kerangka penelitian dibuat untuk mengetahui informasi apa yang melandasi sebuah penelitian agar lebih teratur dan sistematis (Sintaro, Surahman and Prastowo, 2020)

\section{Teknik Pengumpulan Data}

Metode yang digunakan dalam pengumpulan data dan informasi untuk penelitian, diantaranya:

1. Metode Wawancara (Interview) adalah metode pengumpulan data dan informasi dengan cara mengemukakan pertanyaan-pertanyaan secara langsung kepada pihak yang terkait untuk mendapatkan data dan informasi yang dibutuhkan penulis.

2. Metode Pengamatan (Observation) merupakan metode pengumpulan data yang dilakukan melalui pengamatan dan pencatatan secara langsung serta mempelajari segala sesuatu yang berhubungan dengan sistem yang sedang berjalan di perusahaan tersebut.

3. Tinjauan Pustaka (Study Literature) merupakan metode pengumpulan data dengan cara membaca, mencatat, mengutip dan mengumpulkan data-data secara teoritis dari buku-buku maupun jurnal yang ada sebagai landasan dalam memecahkan permasalahan yang diangkat oleh penulis.

4. Dokumentasi (Documentation) merupakan teknik pengumpulan data yang dilakukan dengan mempelajari material yang menggambarkan sistem yang sedang berjalan. Biasanya dokumen yang diamati berupa form, laporan, dan grafik organisasi. 


\section{Metode Analisis PIECES}

Analisis merupakan tahapan dimana penulis melakukan identifikasi terhadap masalah yang diperoleh setelah melakukan tahap pengumpulan data, identifikasi masalah yang dilakukan yaitu menggunakan analisis PIECES (Darwis, Pasaribu and Surahman, 2019).Identifikasi masalah dapat dilihat pada gambar dibawah ini

Tabel 1. Analisis PIECES

\begin{tabular}{|c|c|c|}
\hline Analisis & Kelemahan Sistem Lama & Sistem Yang Diajukan \\
\hline Performance & $\begin{array}{l}\text { Kinerja sistem yang lama dalam pengumpulan } \\
\text { data HCR dan OCR masih di lakukan manual } \\
\text { menggunakan kertas formulir sehingga } \\
\text { menimbulkan kesalahan pengisian serta } \\
\text { tercecernya berkas. }\end{array}$ & $\begin{array}{l}\text { Kinerja system baru di lakukan secara } \\
\text { terkomputerisasi menggunakan } \\
\text { perangkat lunak untuk proses } \\
\text { pengumpulan data HCR dan OCR. }\end{array}$ \\
\hline \multirow[t]{2}{*}{ Information } & $\begin{array}{l}\text { Pembuatan laporan dilakukan } \\
\text { dengan merekap kembali form }\end{array}$ & $\begin{array}{l}\text { Laporan akan di generate secara } \\
\text { otomatis oleh sistem dan }\end{array}$ \\
\hline & $\begin{array}{l}\text { HCR dan OCR dari karyawan dan di sortir } \\
\text { kembali secara manual yang bias menyebabkan }\end{array}$ & $\begin{array}{l}\text { menghasilkan } \\
\text { lebihakurat }\end{array}$ \\
\hline Economy & $\begin{array}{l}\text { Perusahaan harus mengeluarkan } \\
\text { biaya untuk mencetak formulir dan melakukan }\end{array}$ & $\begin{array}{l}\text { Perusahaan hanya perlu } \\
\text { mengeluarkan biaya maintenance yang }\end{array}$ \\
\hline Control & $\begin{array}{l}\text { Proses penginputan formulir HCR } \\
\text { dan OCR dilakukan dengan cara menulis manual }\end{array}$ & $\begin{array}{l}\text { Sistem akan memudahkan } \\
\text { control sehingga kemungkinan terjadinya }\end{array}$ \\
\hline Efficiency & $\begin{array}{lcc}\text { Penginputan } & \text { secara manual } \\
\text { menggunakan } & \text { kurang efisien karena perlu }\end{array}$ & $\begin{array}{l}\text { Sistem yang terkomputerisasi } \\
\text { lebih efisien karena penginputan dapat }\end{array}$ \\
\hline Service & $\begin{array}{lcrl}\text { Pembuatan } & \text { laporan } & \text { serta } & \\
\text { pengumpulan laporan } & \text { untukUnit Induk harus }\end{array}$ & $\begin{array}{l}\text { Pembuatan laporan akan di } \\
\text { lakukan secaraotomatis oleh sistem dan }\end{array}$ \\
\hline
\end{tabular}

\section{HASIL DAN PEMBAHASAN}

\section{Usecase Diagram}

Use case diagram merupakan salah satu diagram dalam bahasa pemodelan UML yang dapat menggambarkan kegiatan yang dilakukan oleh aktor secara garis besar, dan hubungan antara aktor dengan tiap kegiatan (actoruse case) atau hubungan antara kegiatan (use case-use case) (Indra, Thyo and Rahman, 2020). 


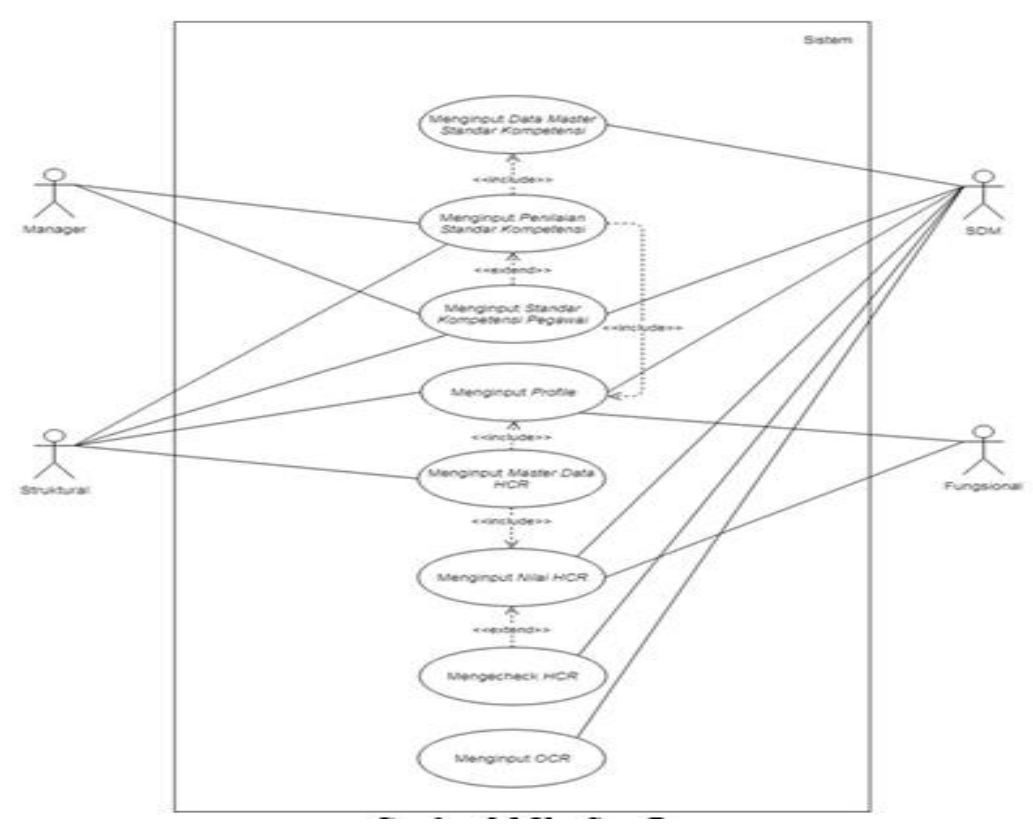

Gämbär1. Usècasè Diāgram

Class diagram yang digunakan untuk menggambarkan proses Sistem Informasi Kinerja Bagian SDM di PT PLN (Persero) Unit Pelaksana Pembangkitan Tarahan 


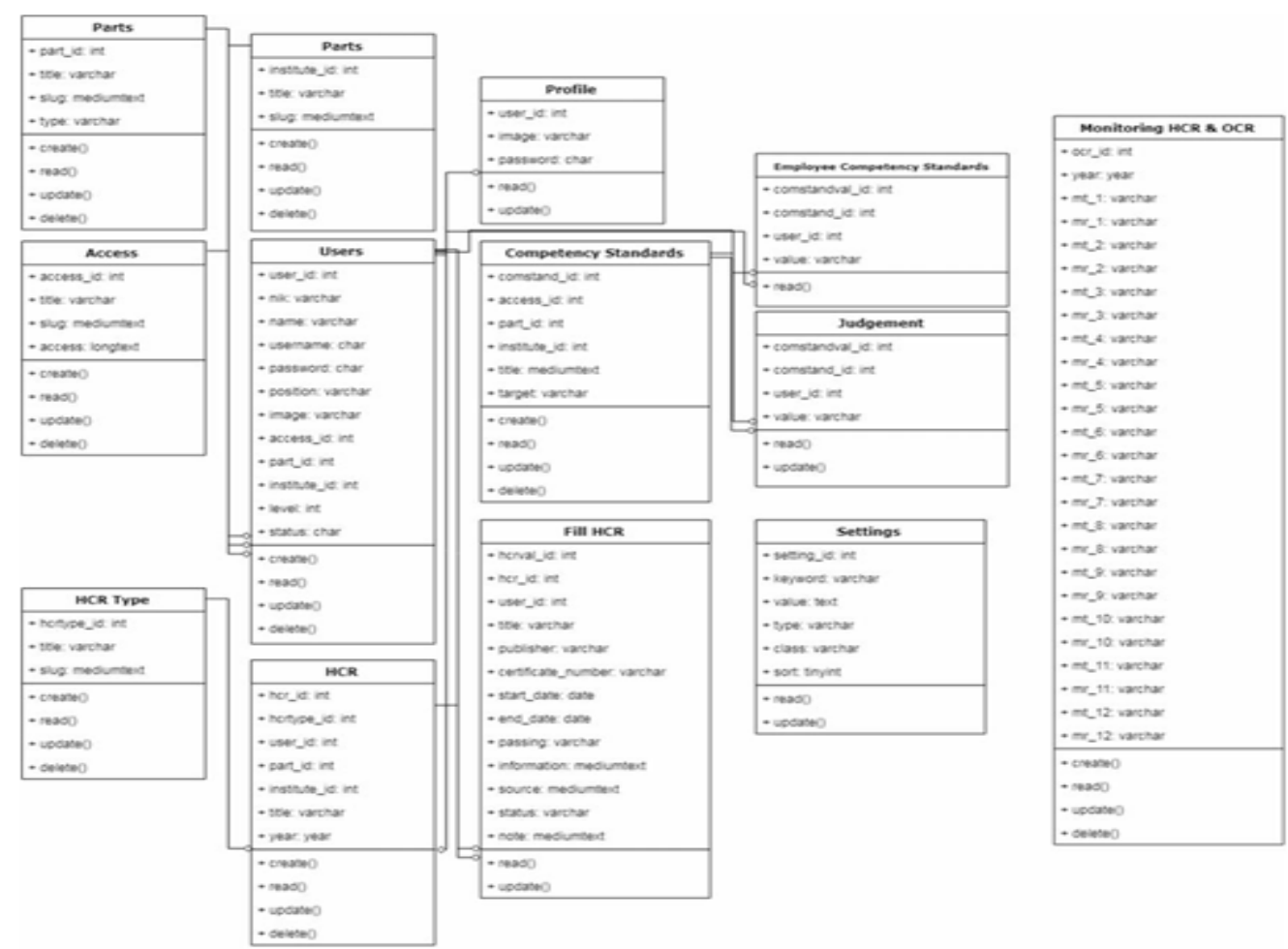

\section{Implementasi}

Gambar 2. Class Diagram

Implementasi sistem merupakan tahapan untuk mengimplementasikan sistem yang telah dibuat. Tahap penggunaan sistem ini dilakukan setelah sistem selesai dievaluasi, kemudian peneliti melaksanakan pelatihan terhadap semua actor yang akan menggunakan sistem, dengan memberikan pengertian dan pengetahuan yang cukup tentang sistem pendukung keputusan yang akan diterapkan. Hal ini dimaksudkan agar pengguna memahami prosedur kerja sistem tersebut, serta dapat mengurangi kesalahan-kesalahan yang akan timbul, sehingga tujuan sistem yang telah dibuat ini dapat tercapai (Rahmanto, Hotijah and Damayanti, 2020).

Pengguna harus login terlebih dahulu untuk bisa mengakses menu yang ada dalam status login pengguna sistem, berikut ini merupakan tampilan implementasi login system

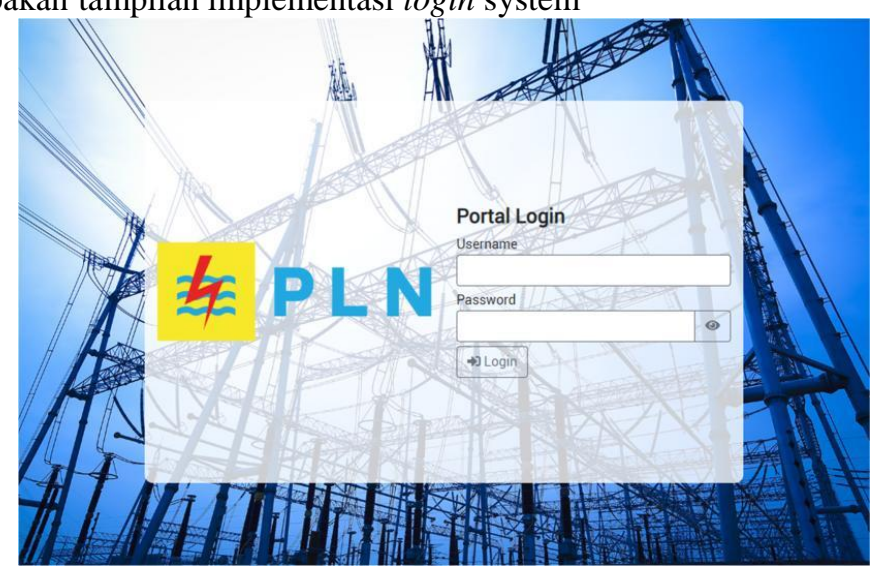

Gambar 3. Halaman Login 
Halaman dashboard pada sistem merupakan halaman yang pertama kali muncul setelah login dan dapat di akses oleh semua actor di dalam sistem ini. Halaman ini berisi data tahun, deskripsi, parameter serta grafik dari kinerja HCR dan OCR, berikut ini merupakan tampilan implementasi halaman dashboard

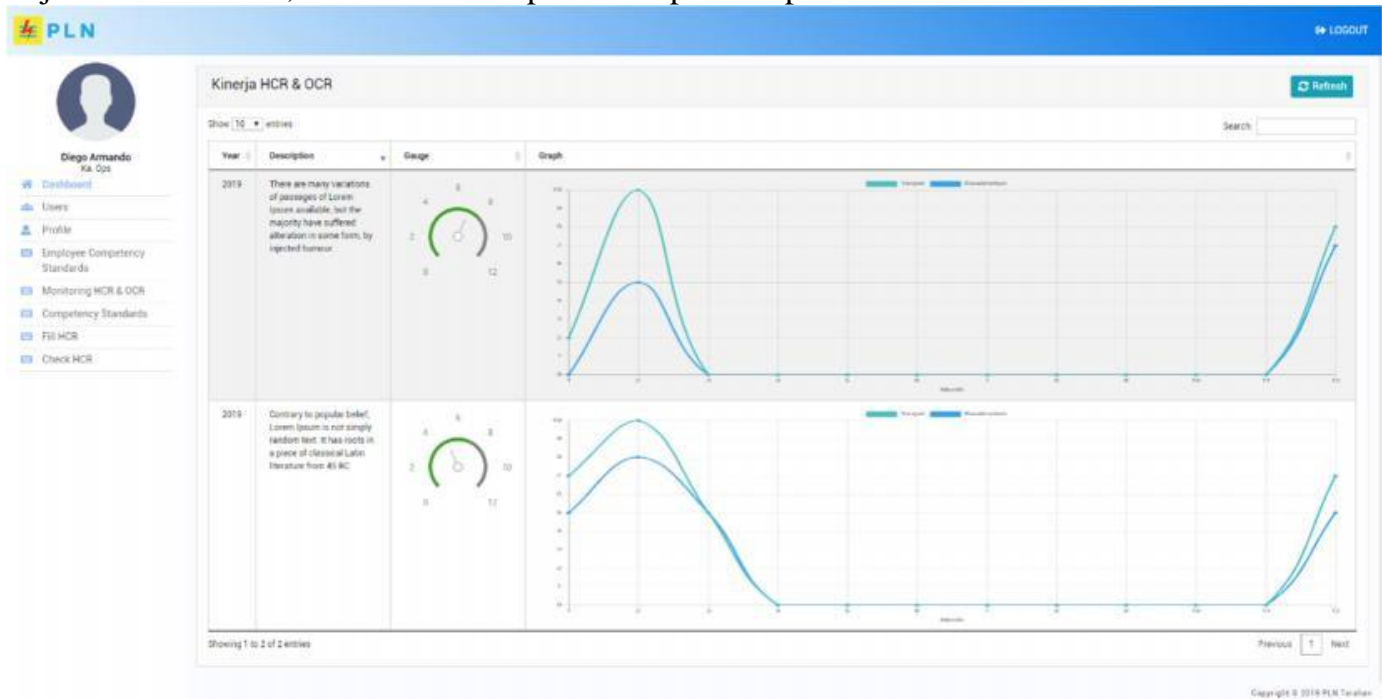

Gambar 4. Halaman Dashboard

Implementasi Halaman Monitoring HCR dan OCR merupakan halaman untuk mengedit data target dan realisasi dari bulan pertama sampai ke bulan duabelas serta di tabelnya juga tersedia informasi deskripsi dan tahun serta ada tombol action yang berguna untuk mengedit data tahun dan deskripsi serta tombol hapus untuk menghapus data tersebut. Halaman ini juga tersedia tampilan visual berupa gauge dan graphic target dan realisasi

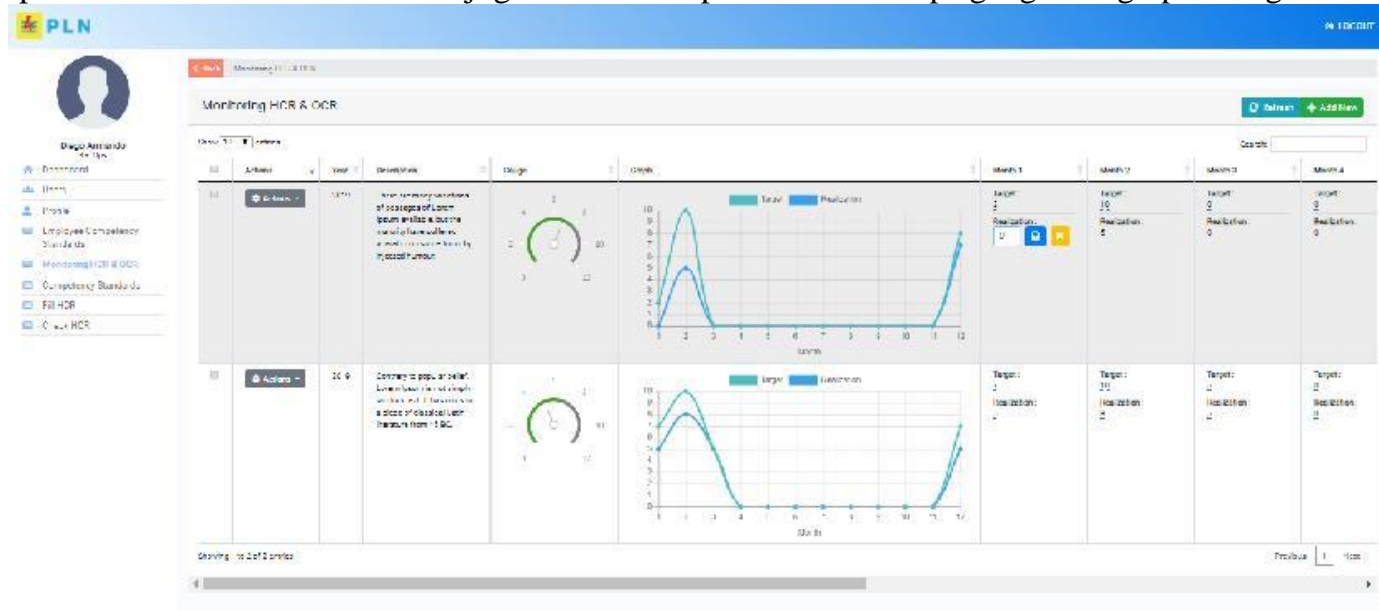

Gambar 5. Halaman Monitoring

Implementasi Halaman Competency Standards merupakan halaman yang berisi tabel data competency standards yang di telah di input. Dan disini terdapat tombol refresh untuk merefresh table serta ada tombol add 
new untuk menuju ke halaman competency standards serta di table terdapat tombol action yang berisi menu untuk edit data dan hapus data

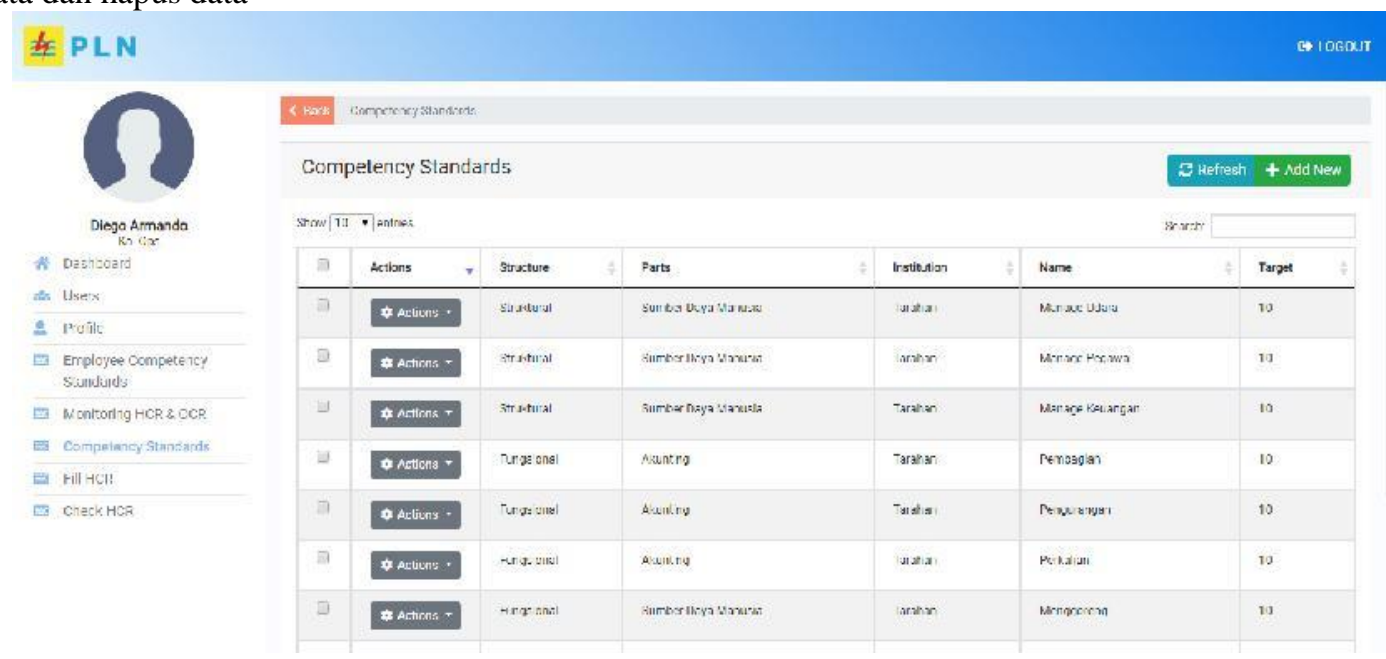

Gambar 6. Halaman Competency Standards

Implementasi Halaman HCR merupakan halaman yang berisi table data HCR yang telah terinput sebelumnya serta terdapat beberapa tombol seperti refresh untuk merefresh table, tombol hcr type untuk menuju halaman hor type, tombol add new untuk menuju halaman add new HCR.

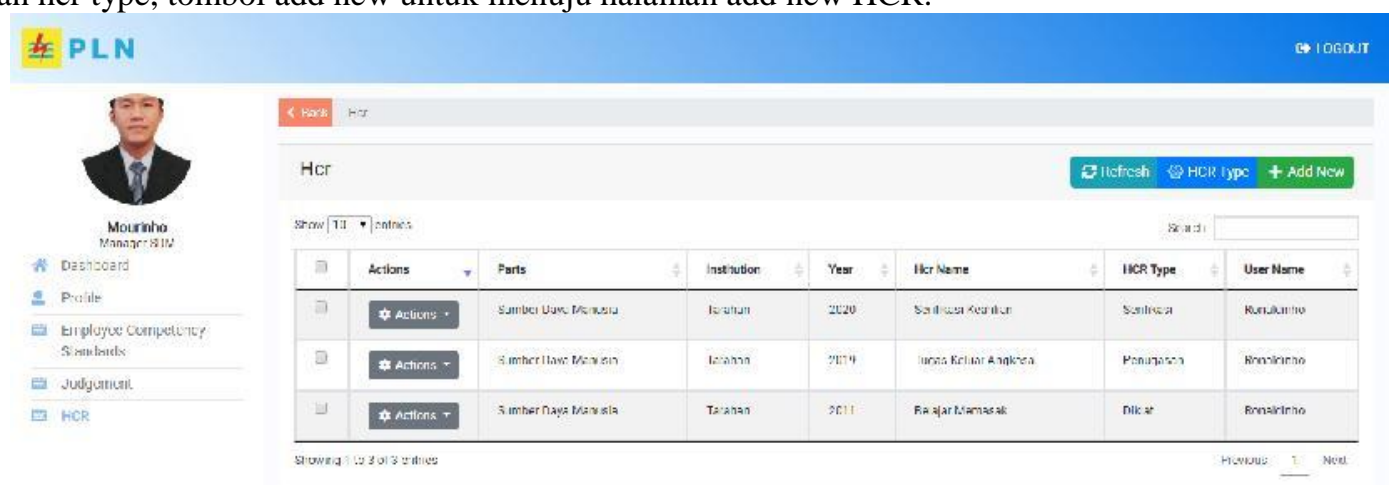

Gambar 7. Halaman HRC

Implementasi Halaman Check HCR merupakan halaman yang berisi table data Check HCR yang terbagi menjadi dua tab, tab pertama ada not currated yang berarti data yang belum di kurasi dan tab already currated yang berarti data telah di kurasi. Di dalam table ada kolom currated dan terdapat tombol currated untuk menkurasi data HCR dan tombol view data untuk melihat data HCR yang telah di isi serta tombol edit di tab already filled in untuk melihat data hor yang telah dikurasi. 


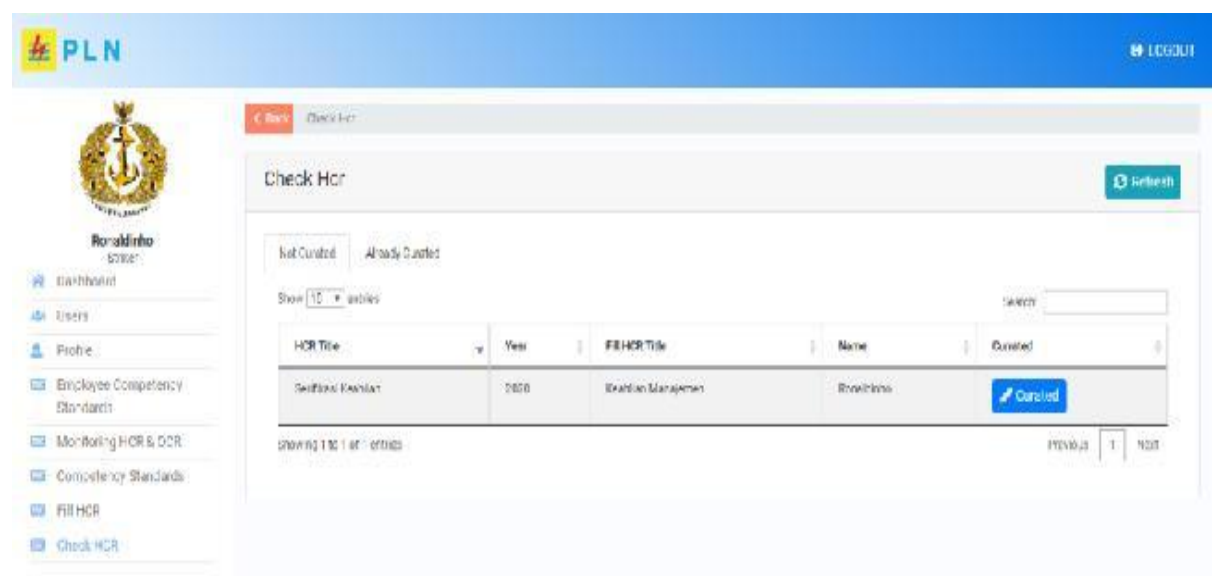

Gambar 8. Halaman Check HRC

\section{Pengujian Sistem}

Pengujian kuesioner dilakukan dengan tujuan untuk mengetahui sejauh mana kualitas dari perangkat lunak yang dibangun, apakah sudah sesuai dengan harapan atau belum (Ahmad et al., 2018). Untuk itu dalam pengujian dilakukan penelitian dengan cara memberikan kuesioner pada calon pengguna perangkat lunak.

\begin{tabular}{|c|c|c|c|c|c|c|c|c|c|c|c|c|c|}
\hline \multirow{2}{*}{$\begin{array}{l}\text { Kriteria } \\
\text { Jawaban }\end{array}$} & \multirow{2}{*}{ Bobot } & \multicolumn{11}{|c|}{ Jumlah Pernyataan } & \multirow[t]{2}{*}{ Total } \\
\hline & & 1 & 2 & 3 & 4 & 5 & 6 & 7 & 8 & 9 & 10 & 11 & \\
\hline Sangat Setuju & 5 & 1 & 1 & & & & & & 1 & 1 & 1 & & 5 \\
\hline Setuju & 4 & & & 1 & 1 & 1 & 1 & 1 & & & & 1 & 6 \\
\hline Ragu-ragu & 3 & & & & & & & & & & & & 0 \\
\hline Tidak Setuju & 2 & & & & & & & & & & & & 0 \\
\hline $\begin{array}{c}\text { Sansat Tirlak } \\
\text { Setuju }\end{array}$ & 1 & & & & & & & & & & & & 0 \\
\hline \multicolumn{2}{|c|}{ Jumlah Responden } & 1 & 1 & 1 & 1 & 1 & 1 & 1 & 1 & 1 & 1 & 1 & \\
\hline \multicolumn{2}{|c|}{ Skor Alktual } & 5 & 5 & 4 & 4 & 4 & 4 & 4 & 5 & 5 & 5 & 4 & 49 \\
\hline \multicolumn{2}{|c|}{ Slior Ideal } & 5 & 5 & 5 & 5 & 5 & 5 & 5 & 5 & 5 & 5 & 5 & 55 \\
\hline
\end{tabular}

$$
\begin{aligned}
\% \text { Skor Aktual } & =\frac{\text { Skor Aktual }}{\text { Skor Ideal }} \times 100 \% \\
& =\frac{49}{55} \times 100 \% \\
& =89.09 \%(\text { Kriteria Sangat Baik) }
\end{aligned}
$$

Berdasarkan hasil kuesioner yang telah dibagikan ke karyawan/karyawati PT PLN (Persero) Unit Pelaksana Pembangkitan Tarahan, sistem ini mendapatkan hasil persentase angka dengan nilai $89.09 \%$.

\section{SIMPULAN (11 PT)}

Berdasarkan pembahasan penelitian tentang monitoring kinerja sebagai upaya untuk membantu Bagian SDM PT PLN (Persero) Unit Pelaksana Pembangkitan Tarahan mencapai target-target yang hendak diselesaikan, maka dapat disimpulkan bahwa Merancang dan mengimplementasikan sistem monitoring kinerja dengan menggunakan metode Key Performance Indicator (KPI) dapat membantu bagian SDM dalam memantau kinerja 
perusahaan untuk membantu mencapai Nilai Kinerja Organisasi (NKO). Sistem monitoring ini menggunakan model pengembangan sistem prototype, dengan rancangan sistem menggunakan pemodelan visual yaitu UML seperti use case diagram, activity diagram, dan class diagram. Berdasarkan hasil kuesioner yang telah dibagikan ke karyawan/karyawati PT PLN (Persero) Unit Pelaksana Pembangkitan Tarahan, sistem ini mendapatkan hasil persentase angka dengan nilai $89.09 \%$. Sehingga dengan adanya sistem monitoring pada PT PLN (Persero) Unit Pelaksana Pembangkitan Tarahan dapat membantu pimpinan dalam pengambilan keputusan menentukan strategi perusahaan selanjutnya.

\section{UCAPAN TERIMA KASIH}

Puji syukur penulis panjatkan kepada Allah SWT, karena atas berkat dan rahmat-Nya, penulis dapat menyelesaikan penelitian ini. Penulisan Penulis menyadari bahwa, tanpa bantuan dan bimbingan dari berbagai pihak, dari masa perkuliahan sampai pada penyusunan penelitian ini. Oleh karena itu, penulis mengucapkan terima kasih kepada:

1. Bapak Dr.H.M. Nasrullah Yusuf S.E, M.B.A., selaku Rektor Universitas Teknokrat Indonesia;

2. Bapak Dr. H. Mahathir Muhammad, S.E., M.M., selaku Dekan Fakultas Teknik dan Ilmu Komputer, Universitas Teknokrat Indonesia;

3. Ibu Dyah Ayu Megawaty, M. Kom. selaku Ketua Program S1 Informatika, Fakultas Teknik dan Ilmu Komputer, Universitas Teknokrat Indonesia;

\section{REFERENSI/DAFTAR PUSTAKA}

Ahmad, I. et al. (2018) 'Using Fuzzy K-Nearest Neighbor for Predicting University Students Graduation In Teknokrat', Indonesian Journal of Artificial Intelligence and Data Mining (IJAIDM), 1(1), pp. 47-52.

Darwis, D., Pasaribu, A. F. and Surahman, A. (2019) 'Sistem Pencarian Lokasi Bengkel Mobil Resmi Menggunakan Teknik Pengolahan Suara dan Pemrosesan Bahasa Alami', Jurnal Teknoinfo, 13(2), pp. 71-77.

Indra, R., Thyo, A. and Rahman, A. (2020) 'Implementasi Metode Pengembangan Sistem Extreme Programming ( XP ) pada Aplikasi Investasi Peternakan Implementation of Extreme Programming ( XP ) System Development Method in Livestock Investment Aplication', 8(3), pp. 272-277. doi: 10.26418/justin.v8i3.40273.

Mangkunegara, A. A. A. P. (2005) Evaluasi kinerja SDM. Tiga Serangkai.

Megawaty, D. A. et al. (2020) 'SISTEM MONITORING KEGIATAN AKADEMIK SISWA', 14(2), pp. 98-101.

Parmenter, D. (2015) Key performance indicators: developing, implementing, and using winning KPIs. John Wiley \& Sons.

Rahmanto, Y., Hotijah, S. and Damayanti (2020) 'PERANCANGAN SISTEM INFORMASI GEOGRAFIS KEBUDAYAAN LAMPUNG BERBASIS MOBILE', JDMSI, 1(3), pp. 19-25.

Setiawansyah, Sulistiani, H. and Darwis, D. (2020) 'Penerapan Metode Agile untuk Pengembangan Online Analytical Processing ( OLAP ) pada Data Penjualan ( Studi Kasus : CV Adilia Lestari )', Jurnal CoreIT, 6(1), pp. 50-56.

Sintaro, S., Surahman, A. and Prastowo, A. T. (2020) 'PENERAPAN WEB WALKERS SEBAGAI MEDIA INFORMASI UNTUK PERBANDINGAN MANUAL BREWING COFFEE DI INDONESIA’, JSiI (Jurnal Sistem Informasi), 7(2), pp. $132-137$. 